\title{
The construction of ethnic identity: insights from identity process theory
}

\author{
Rusi Jaspal* \\ Institute for Science and Society, School of Sociology and Social Policy, University of \\ Nottingham \\ Marco Cinnirella \\ Department of Psychology, Royal Holloway, University of London
}

To cite this article: Jaspal, R. \& Cinnirella, M. (in press). The construction of ethnic identity: insights from identity process theory. Ethnicities.

* Correspondence: Dr Rusi Jaspal, Institute for Science and Society, School of Sociology and Social Policy, Law and Social Sciences Building, University of Nottingham, Nottingham NG7 2RD, United Kingdom. E-mail: rusi.jaspal@ gmail.com

\section{AUTHOR BIOGRAPHIES}

Rusi Jaspal is a Social Psychologist and Research Fellow at the Institute for Science and Society (School of Sociology and Social Policy) at the University of Nottingham. He has a long-standing interest in the inter-relations between social representation, identity and social action. His current research explores the social psychology of anti-Semitic prejudice and the social construction of climate change.

Marco Cinnirella obtained his PhD in Social Psychology from the London School of Economics. He is currently a Senior Lecturer in Social Psychology at Royal Holloway, University of London, where his research focuses on applied aspects of intergroup relations and social identity.

\section{ACKNOWLEDGEMENTS}

The authors would like to thank Professor Glynis Breakwell, Dr Anat Bardi and the Social Psychology Research Group at Royal Holloway, University of London for providing valuable comments on earlier versions of this paper. This paper has also benefited from insightful comments from several anonymous reviewers. The research was supported by a Thomas Holloway research grant awarded to the first author. 


\title{
The construction of ethnic identity: insights from identity process theory
}

\author{
Rusi Jaspal \\ University of Nottingham \\ Marco Cinnirella \\ Royal Holloway, University of London
}

\begin{abstract}
Ethnicity has received much empirical and theoretical attention in the social sciences. Yet, it has scarcely been explored in terms of its relationship with the motivational principles of identity. Here it is argued that there is much heuristic and predictive value in applying identity process theory (IPT), a socio-psychological model of identity threat, to the substantive literature on ethnicity. The paper explores the potential psychological benefits of ethnic identification. Key theoretical strands from anthropology and sociology such as the 'relational self' in ethnic identification are discussed in relation to IPT. The intergroup dimension of ethnic identification is explored through the discussion of ethnic 'boundaries'. Finally, the paper discusses the construct of 'hybridisation' in relation to social psychology. This paper attempts to reconcile psychological and sociological perspectives on ethnic identification, advocating a multi-methodological approach. Key theoretical points are outlined in the form of testable hypotheses which are open to empirical exploration.
\end{abstract}

Keywords: ethnic identity; ethnicity; hybridity; identity threat; identity process theory; social representations; South Asians; social psychology; sociology

Ethnic identity is one dimension of the self which has received much empirical and theoretical attention in the social sciences, given its wide-ranging implications for inter alia intergroup relations (Hofman, 1988; Verkuyten, 2005), linguistic behaviour (Jaspal \& Coyle, 2009, 2010a, 2010b) and psychological well-being (Taylor \& Brown, 1988; Phinney et al., 2001). In recent times, social psychologists, sociologists and anthropologists have discussed ethnic identity construction among British South Asians (BSA; Modood et al., 1997; Ghuman, 2003; Robinson, 2009; Hutnik \& Street, 2010). However, ethnic identification has scarcely been explored in terms of its relationship with the motivational principles of identity. This paper will argue that it is useful to consider the basic motivational principles of identity, highlighted by socio-psychological approaches to identity and identity threat, in order to understand the construction of ethnic identity. Conversely, such an approach enables the researcher to predict the more general outcomes of ethnic identification for the self-concept. Like any dimension of the self, ethnic identity is understood to constitute a dynamic social product, which resides in psychological processes (Breakwell, 1986). Moreover, sociocultural and socio-historical conditions generate and maintain specific patterns of ethnic identification among individuals. This reveals the importance of employing a sociopsychological approach which synthesises intrapsychic and socio-cultural levels of analysis.

The present paper begins by presenting the basic tenets of IPT, which is said to offer much heuristic value for understanding ethnic identity construction. The socio-psychological functions of ethnic identity will be discussed. Moreover, IPT is invoked in order to consider some of the psychological benefits of ethnic identification. The paper considers how ethnic identity is constructed, the role of the 'relational self' in ethnic identity construction, as well as how processes of inclusion and exclusion in the ethnic group may be manifested by group members. The final sections of this paper discuss the role of ethnic identity within the 
broader context of multiple identities including how individuals might manage and reconcile these identities. Relevant strands of IPT are drawn upon in order to interpret key concepts from the vast social sciences literature on ethnic identity construction.

The objective of the present paper is two-fold, namely; (i) to explore and to explicate the processes underlying ethnic identity construction, including the predicted psychological outcomes of ethnic identification and the predicted patterns of ethnic self-categorisation; and (ii) to demonstrate the heuristic value in IPT for understanding the construction of ethnic identity. Much of the literature cited in this paper concerns BSA in general - when we refer to specific subsections of this population (e.g. first or second generation), this is indicated in the paper. While most of the empirical examples employed in the present paper originate from previous research among BSA, many of the theoretical arguments presented are likely to be applicable to ethnic identity more broadly. In this paper we employ existing research as a vehicle for contributing to general research and theory concerning ethnic identity construction. During the course of the discussion, key theoretical points are outlined in the form of hypotheses which are open to empirical exploration. This is not meant to represent a pre-determined 'road-map' for future research on ethnic identity, but rather as a means of providing explicit research questions which could guide future work in this area.

\section{Theoretical framework}

Some of the major debates on ethnic identity include issues around its contribution to the self, how individuals cope with threats to the self, and what motivates individuals and groups to defend it. Given the focus upon motivational principles associated with identity processes in identity process theory (IPT; Breakwell, 1986, 1992, 2001; Jaspal \& Cinnirella, 2010a; Vignoles et al., 2006), it is suggested that the theory possesses much heuristic value for understanding these issues. IPT proposes that the structure of identity should be conceptualised in terms of its content and value/ affect dimensions and that this structure is regulated by two universal processes, namely the assimilation-accommodation process and the evaluation process. The assimilation-accommodation process refers to the absorption of new information in the identity structure and the adjustment which takes place in order for it to become part of the structure. The evaluation process confers meaning and value on the contents of identity.

Breakwell $(1986,1992)$ has identified four identity principles which are said to guide these universal processes, namely continuity across time and situation, uniqueness or distinctiveness from others, feeling confident and in control of one's life and feelings of personal worth or social value. IPT refers to these, respectively, as continuity, distinctiveness, self-efficacy and self-esteem. Extending IPT, Vignoles and colleagues (Vignoles et al., 2002; Vignoles et al., 2006) have proposed two additional identity 'motives', namely belonging, which refers to the need to maintain feelings of closeness to and acceptance by other people, and meaning, which refers to the need to find significance and purpose in one's life. More recently, Jaspal and Cinnirella (2010a) have introduced the psychological coherence principle, which refers to the motivation to establish feelings of compatibility between their (interconnected) identities. The theory suggests that when any of these identity principles are obstructed by changes in the social context, for instance, identity is threatened and the individual will engage in coping strategies to alleviate the threat. A coping strategy is defined as 'any activity, in thought or deed, which has as its goal the removal or modification of a threat to identity' (Breakwell, 1986, p. 78).

There are a number of factors which elucidate the greater heuristic value in IPT vis-àvis competing theories such as optimal distinctiveness theory (Brewer, 1991) and the identity integration model (Amiot et al., 2007). Firstly, the foci of these frameworks are all accounted for by and incorporated in IPT. It constitutes a broad and inclusive framework which 
provides the analytic tools necessary to consider the opposing motives of distinctiveness and belonging (optimal distinctiveness theory) and identity coherence. Crucially, its integrative nature enables the researcher to consider the relationships between the identity principles, which remains an important, and largely under-explored, theoretical question in the IPT literature (Breakwell, 1986; Jaspal \& Cinnirella, 2010a). While the aforementioned theories elucidate the opposing needs for belonging and distinctiveness and for identity coherence, respectively, they provide little insight into the possible implications of optimal distinctiveness or identity integration for the principles of continuity, self-efficacy and meaning. IPT, on the other hand, is sufficiently flexible so as to offer predictions regarding not only the inter-relations between the principles but also the more general outcomes for the self-concept.

Secondly, the focus of optimal distinctiveness theory and identity integration is primarily at the intergroup level; indeed, both are rooted within the social identity tradition. IPT, on the other hand, abandons the distinction between social and personal identity, since 'seen across the biography, social identity is seen to become personal identity: the dichotomy is purely a temporal artefact' (Breakwell, 2001, p. 277). IPT does acknowledge the existence of social identities and individual traits, as well as the potentially differential consequences of these phenomena for the self-concept. Relative to the self-concept, these may be regarded in terms of self-aspects. IPT conceptualises identity in terms of the unique constellation of selfaspects which every individual possesses and 'which mark him or her as a unique person, different in psychological profile from all others' (Breakwell, 1986, p. 12). This reflects the conceptualisation of identity employed in the present paper.

Breakwell's theory is one of the few socio-psychological frameworks which successfully integrate the micro, macro and meso levels of human interdependence. This is especially evident in IPT's explicit recognition of the role of social representations in the psychosocial processes which underlie identity construction (Breakwell, 2001; Moscovici, 1988). Theoretical and empirical approaches to ethnic identity within the social sciences clearly attest to the need for an integrative consideration of ethnic identity, which includes both the macro and micro levels (Scott, 1990; Smaje, 1997). IPT offers such an integrative approach. Thus, as a broad and integrative theoretical framework, IPT may be regarded as a particularly valuable theoretical tool with which to consider the construction of potentially complex ethnic identities as manifested by BSA and possibly other populations (Ghuman, 2003; Jacobson, 1997; Vadher \& Barrett, 2009).

IPT has received a great deal of empirical support, both quantitative and qualitative, which suggests that it constitutes a robust theoretical tool particularly within the area of identity construction. It has been employed to explore a variety of socio-psychological topics, including the identity implications of migration and relocation (Speller, 2000; Timotijevic \& Breakwell, 2000) and the management of potentially conflictual identities (Jaspal \& Cinnirella, 2010a). IPT is explicitly concerned with the effects of social change upon identity construction (Breakwell, 1986, 1996; Lyons, 1996). These are important factors underlying our decision to advocate the use of IPT in studies of ethnic identity construction. Here it is argued that there exists a need for a broad, inclusive theory of identity threat, such as IPT, which identifies multiple identity principles and which provides scope for the exploration of intrapsychic, not just interpersonal and intergroup, processes.

One of the major credentials of IPT lies in its identification, description and elaboration of the various coping strategies in which individuals will engage upon perceiving identity to be threatened. Thus, IPT is not only a theory of identity construction, outlining the conditions under which identity processes operate successfully. It also predicts the ways in which the individual will react to threatened identity. These strategies are fluid and subjective since different forms of identity threat will require the use of distinct coping 
strategies. Moreover, some strategies are said to be more effective than others in the long-run (Jaspal \& Cinnirella, in press). The individual's choice of coping strategy may differ according to the level of human interdependence; IPT identifies intrapsychic, interpersonal and intergroup coping strategies (Breakwell, 1986). While coping strategies may fit broadly within these three levels of human interdependence, they are likely to differ qualitatively according to the individual and/ or culture in question. IPT theorists have identified and described coping strategies not originally accounted for by the theory (e.g. Timotijevic, 2000; Jaspal \& Cinnirella, 2010a), and the theory actively encourages this. By conceptualising the behaviour intended to safeguard and enhance the principled operation of identity processes as coping strategies, IPT researchers may be able to theorise the inter-relations between behaviour and ethnic identity. This is one of the aims of the present paper.

Given the centrality of identity threat in the theory, one might plausibly wonder why BSA are possibly more susceptible to identity threat than other populations, for instance. There are various reasons for believing that BSA may occupy 'threatening positions', which is conceptually distinct from the actual experience of identity threat. Firstly, it has been observed that individuals might experience difficulties in reconciling their ethnic and national identities, given the differing norms, values and social representations associated with these identities (Ghuman, 2003, 2005; Jaspal \& Coyle, 2010b; Vadher \& Barrett, 2009). According to IPT, this may compromise the psychological coherence principle of identity (Jaspal \& Cinnirella, 2010a). Secondly, it has been observed that some, particularly second generation, BSA feel excluded from the national category British by the White British majority because the practices, norms and values associated with their ethnic identities may be widely perceived to be incompatible with Britishness (Hopkins, 2004; Jacobson, 1997; Vadher \& Barrett, 2009). The otherisation of BSA possibly as a result of the reported rise in Islamophobic prejudice is likely to pose threats to the belonging principle of identity (Sheridan, 2006; Vignoles et al., 2006). Furthermore, if rejection is perceived to result from the 'negativity' of their membership in the ethnic group or if the social 'status' of their ethnic ingroup is perceived to be weak (Jaspal, 2011), this may have adverse repercussion for the self-esteem principle (Breakwell, 1986; Jaspal \& Sitaridou, 2010). Thirdly, Jaspal and Coyle (2009, 2010b) observed in their interview studies with BSA that participants identified aspects of their ethnic identities as posing threats to the distinctiveness principle, since they reportedly felt unable to stand out as unique individuals in certain social contexts. While participants manifested strategies for coping with threats to distinctiveness, these threats were said to re-occur. These examples from previous empirical research into ethnic identity among BSA provide some evidence to support the hypothesis that BSA occupy threatening positions in relation to their ethnic experience. However, it must be reiterated that the occupancy of a threatening position is by no means synonymous with the actual subjective experience of identity threat (Breakwell, 1986). In order for identity to be threatened, the threat must gain access to the individual's consciousness. This is not to say that threats only exist at the intra-psychic level - on the contrary, they are debated and discussed in discourse and embodied in social representations circulating in society, and these inform individuals' own interpretations of them. Research on the role of emotion in identity threat reveals ways in which researchers may be able to identify identity threat among participants (Timotijevic, 2000). This useful conceptual distinction forms part of our rationale for considering IPT a model of identity construction and identity threat appropriate for use in research into ethnic identity construction.

\section{Towards a conceptualisation of ethnicity}

There is an abundant literature on ethnicity spanning across several academic disciplines. The topic has been addressed by anthropologists (e.g. Eriksen, 1993, 2001), by sociologists 
(e.g. Mason, 2000; Rex, 2004) and by social psychologists (e.g. Phinney, 1996; Verkuyten, 2005; Zagefka, 2009). Most researchers (e.g. Smith, 1998; Sternberg et al., 2005) agree that ethnicity is constructed (subject to personal agency) rather than primordial (based upon immutable biological difference). However, the extent to which human agency is understood to determine ethnicity frequently varies according to the epistemological position of the researcher. For instance, some social scientists (e.g. Balibar \& Wallerstein, 1991) argue that ethnicity is largely fictive and exists only within discourse, while others (e.g. Phinney, 1996) view ethnic identity as being subject to societal constraints and to perceptions of others. Indeed, 'voluntary ethnicity', or a unilateral claim to an ethnic identity, is unlikely to be possible since the identity must be 'validated' by significant others (Jaspal \& Coyle, 2009, 2010b; Reicher \& Hopkins, 2001).

For Abizadeh (2001), 'ethnicity is based on mythical beliefs about the genealogical facts, not the genealogical facts themselves [..] the myths themselves can often be based on historically inaccurate beliefs. [Ethnicity] [..] exists as a socially constructed category contingent on beliefs. [..] Ethnicity's very existence is dependent on beliefs about its existence' (p. 25; italics added). This definition emphasises the social constructedness of ethnicity, which constitutes a presumed identity and a belief in common descent. Though socially constructed, ethnic demarcation lines 'are 'real' in the sense that they form an important part of people's psychological realities' (Zagefka, 2009, p. 231). Similarly, Geertz (1973) postulates that, while ethnicity itself is not primordial (based upon immutable biological difference), it is often viewed as such by individuals who lay claim to an ethnic identity. Thus, primordialism is not inherent in an ethnicity, but rather it is attributed to it (Verkuyten, 2005). Given its consideration of both social constructionism and primordialism in ethnic identity construction, the present paper adopts this conceptualisation of ethnic identity. Zagefka's (2009) definition subtly demonstrates that although ethnicity is, to a large extent, socially constructed, it is not completely arbitrary. In order for ethnic identity to be 'validated' by significant others, some perceived genealogical 'facts' must support and legitimise claims of ethnic identity. This constitutes our first hypothesis:

\section{Hypothesis 1: The provision of genealogical 'facts' grounded in social representations will lead to the 'validation' of one's ethnic identity, which is an essential process associated with ethnic identity construction.}

It is noteworthy that a range of rhetorical strategies will be employed by social actors in order to render these 'facts' plausible and acceptable to significant others. These include references to inter alia physical similarities, common cultural characteristics, a common language or religion (Verkuyten, 2005). One example of this is that subsequent to the independence of East Pakistan in 1971, Pakistani nationalist politicians sought to highlight the common ethnicity of (and to de-emphasise the many ethnic differences between) all Pakistanis through reference to their common Islamic faith (Tikoo, 2002). This 'fact' was emphasised in order to downplay the many other factors that could potentially suggest the contrary, namely that there indeed are ethnic differences between groups in Pakistan. Thus, it is evident that the emphasis on common religious faith was one of the many rhetorical possibilities available to Pakistani politicians and that the contrary could have been constructed in an equally straightforward fashion, perhaps by reference to the multitude of dialects, languages, traditions, and genealogical differences among Pakistanis (Reicher \& Hopkins, 2001). This example illustrates how an ethnic identity might be justified rhetorically by, firstly, presenting criteria for acceptance as an ethnic ingroup member (i.e. the group's 'historical' self-identification with Islam) and, secondly, by convincing significant others (i.e. aspired ingroup members) that the ethnic identity is based upon genealogical 'facts'. If the two processes are successful, 
the identity is likely to be validated and, thus, to become a socio-psychological 'reality'. It is important to consider why individuals lay claim to an ethnic identity by exploring the potential psychological benefits of ethnic identification.

\section{The psychological benefits of ethnic identification}

The nature of the psychological functions performed by identification with an ethnic group remains an important theoretical question. According to Phukon (2002), the term 'ethnic' refers to a sense of belonging and togetherness but, more importantly, it can also be understood as 'an organizing principle used by a group of people in order to differentiate themselves from other groups in terms of race, kinship, language, customs, mode of living, culture religion and so on' (p. 1). Laying claim to an ethnic identity is likely to have positive outcomes for the belonging principle since membership in the ethnic group enables the aspiring group member to acquire a sense of closeness to, and acceptance by, other people; indeed, this constitutes a 'fundamental human motivation' (Baumeister \& Leary, 1995, p. 497). This is outlined in hypothesis 2 :

Hypothesis 2: Identification with one's ethnic group will have positive implications for the belonging principle of identity.

Crucially, the sense of belonging associated with membership in one's ethnic group is likely to serve as a buffer against perceived rejection from other social groups, such as from members of the dominant national majority (Jacobson, 1997; Vadher \& Barrett, 2009), resulting in an overall enhanced sense of belonging (Roberts et al., 1999). For instance, in a study on ethnic and national identity among Moluccan adolescents in Holland, Verkuyten et al. (1999) observed that perceived discrimination from the Dutch majority played an important role in participants' relatively greater sense of affiliation to their Moluccan ethnic group.

Moreover, the distinctiveness principle, which refers to a sense of differentiation from others, is likely to be enhanced by perceiving the ingroup as positively distinctive from outgroups (Vignoles et al., 2000). Ethnic identity has been said to arise primarily from group members' social representations of cultural difference 'for ethnicity is essentially an aspect of a relationship' (Eriksen, 1993, p. 12). From a psychological perspective, distinctiveness is likely to constitute a fundamentally important principle associated with ethnic identity construction, as highlighted in hypothesis 3:

Hypothesis 3: The distinctiveness principle of identity will be enhanced by ethnic identification, as ethnic identification is most pertinently associated with distinctiveness.

It has been observed that specific motivational principles may be more (or less) associated with specific identities. For instance, self-efficacy has been said to be less associated with gay identity among British Muslims (Jaspal \& Cinnirella, 2010a). Given the importance of perceived cultural difference between groups in ethnic identity construction (Eriksen, 1993), it is reasonable to hypothesise that (group) distinctiveness is particularly relevant to the construction of this identity. In a content analysis of British Muslims' statements regarding ethnic and national identities (Hutnik \& Street, 2010), it was found that most participants described themselves solely in terms of their ethnic minority identity and were thus 'rooted' in their ethnic minority identity. The authors observe that individuals within this category may emphasise intergroup differences from both the White British majority group and/ or 
other ethnic minority groups. In support of the third hypothesis, this highlights the activeness of the distinctiveness principle among individuals rooted in their ethnic minority identity.

In their study on second generation BSA, Modood et al. (1994, p. 59) found that participants generally exhibited a strong sense of ethnic pride, 'of wanting to know about or at least to affirm one's roots in the face of a history and a contemporary society in which one's ethnicity has been suppressed or tainted with inferiority'. Through the exploration of the socio-historical traditions associated with their ethnicities, individuals may come to construe a long, and perhaps romanticised, ethnic history. This tendency has also been identified by social anthropologists and sociologists who talk of the 'invention of tradition' and the creation of national myths and stories (Smith, 1991). Crucially, this constructed history must serve to endow group members with a positive sense of ethnic identity. Thus, it could be hypothesised that:

Hypothesis 4: In order for ethnic group members to construct a positive ethnic identity, positive social representations of the ingroup's history will become psychologically salient while negative aspects of the ingroup's history will become psychologically latent (see Breakwell, 2001).

The constructed narrative is likely to provide group members with a positive sense of 'continuity across time' (Breakwell, 1986, p. 24). For instance, it has been observed that individuals prefer to distance themselves psychologically from their negative aspects of their ingroup's past such as intergroup violence and ingroup atrocities (Cohen, 2001). This is likely to enhance a positive sense of continuity. In a recent study on language and ethnic identity, it was found that participants generally sought to maintain continuity of selfdefinition as British Asian, that is, in terms of their ethnic identities, primarily because they generally construed their ethnic group membership in positive terms (Jaspal \& Coyle, 2010b). A group member may thereby come to perceive him-/herself not as an independent individual in the world but as part of a long lineage of individuals bound together by a common heritage. This provides ethnic group members with a psychological connection between past, present and future (De Vos, 1995), which is a crucial tenet of the continuity principle.

On a similar note, Jaspal and Cinnirella (2010a) report how British Muslims may highlight the continuity of their ethno-religious identities by highlighting that Islam has changed very little since its foundation centuries ago. They observe that continuity may be enhanced through downward comparisons with other ethno-religious groups (Wills, 1981). Self-identification with the ethnic group may be manifested through personal engagement with ethnic festivals, music, films, media and stories, 'providing a sense of continuity through the ages', as highlighted in a study on Indo-Canadians (Kalkman, 2003, p. 34). As alluded to in this work, the temporal aspect of ethnicity is grasped in the traditions associated with the ethnic group. Traditions constitute the 'common thread' which unite the past, present and future of an ethnic group, thereby enabling ethnic group members to reconnect with the past, to express themselves 'ethnically' in the present and to perceive an enduring ethnic identity in the future. Individuals therefore construct intra-psychically, and also discuss and debate with others, their 'possible ethnic group identities' (Cinnirella, 1998), striving to maintain compatibility and continuity across time and space. Thus, the fifth hypothesis is that:

Hypothesis 5: Thinking about 'immutable' traditions associated with one's ethnic identity will enhance the continuity principle of identity.

In the words of Nash (1989, p. 15), this 'allows for a linkage over generations, thus bestowing upon even the most humble member of the group a pedigree, allowing him [or her] 
to identify with heroic times, great deeds, and a genealogy to the beginning of things human, cultural and spiritual' (see also Smith, 1986). Here there is overlap with theorising about national identity, which makes the similar point that national identity can provide a sense of connection to something immortal, thereby providing a perceived transcendence of human mortality (Doob, 1964).

The notion that this constitutes a positive sense of continuity is likely to have simultaneous benefits for the self-esteem principle, which refers to 'the motivation to maintain and enhance a positive conception of oneself' (Gecas, 1982, p. 20). Indeed, a central assumption of social identity theory is that group members are motivated by a desire to view their ingroup, and by extension themselves, in a positive light, which is conducive to enhanced self-esteem (Brown, 2000). This is highlighted in hypothesis 6:

Hypothesis 6: A positive sense of continuity derived from one's ethnic identity will have positive outcomes for the self-esteem principle.

Having considered some of the psychological benefits of ethnic identification, we now explore some of the socio-psychological processes associated with ethnic identity construction, such as the role of the 'relational self' therein.

\section{The 'relational self' in ethnic identity construction}

Social anthropologists generally view ethnicity as the product of a relational, interactive social process; ethnic groups 'must have a minimum of contact with each other and they must entertain ideas of each other as being culturally different from themselves' (Eriksen, 1993, p. 11-12). Ethnicity is conceptualised as an aspect of a relationship between two or more groups who see themselves as bearing 'cultural differences'. Accordingly, ethnic identity emerges when such differences are made socially relevant (Eriksen, 1993). This notion connects with socio-psychological theorising on the role of the 'significant other' in identity construction (Triandafyllidou, 2001). Hutnik and Street (2010) discuss how individuals rooted in ethnic minority identity may invoke the ethnic groups to which they do not belong in order to elucidate their ethnic identities. In short, group members must collectively discover and define who they are not in order to know who they are, which reflects the importance of the 'relational self' in ethnic identity construction. This is an important point, which should encourage researchers to consider the qualitative nature of intergroup relations in ethnic studies (see Bar-Tal \& Teichman, 2005).

The importance of the 'relational self' is revealed by comparing ethnic self-definitions from BSA and US South Asians. Maira (2002) describes the collective identity category 'desi', which is commonly endorsed and adopted by American-born Indians and Pakistanis. The category 'desi' highlights the common (linguistic) ingroup identity since it means 'from the country' in some languages derived from Sanskrit. Identification with the category 'desi' reflects a common ethnic identity based around self-aspects of a common language and common ethno-cultural traditions. Crucially, in this socio-cultural context American Indians and Pakistanis do not seem to 'entertain ideas of each other as being culturally different from themselves', hence there is but one ethnic identity (Eriksen, 1993, p. 11-12).

However, this can change when ethno-cultural differences become a psychological 'reality' for group members. Social change may be a precursor to ethnic identity construction (Breakwell, 1986). These perceived differences must bear relevance to the social context in order for them to contribute to the formation of distinct ethnic identities. For instance, the category Asian is commonly employed by many Britons whose origins lie in the Subcontinent to refer to their ethnic identity. However, it has been observed that, given the increasingly negative social representations surrounding Islam and the consequential rise in 
Islamophobia (Jaspal \& Cinnirella, 2010b), many non-Muslim South Asians may prefer to define their ethnic identities in much more specific terms (e.g. as Indian, Punjabi, Gujarati, Hindu) in order to differentiate themselves from Muslims (Jaspal, in press). A revivalist British Hindu identity has been observed among some South Asians which may perform the psychological function of maintaining a sense of intergroup differentiation (Raj, 1997, 2000). Thus, it is hypothesised that:

Hypothesis 7: Specific socio-psychological contexts in which group members come to perceive themselves as 'culturally different' will be conducive to the construction of ethnic identity.

This illustrates how the social context may impact self-categorisation (Turner et al., 1987) and, more specifically, that social change (i.e. the rise in Islamophobia) can re-activate 'dormant' social representations highlighting inter-ethnic difference (Cinnirella, 1997).

This process will in turn lead individuals to identify with the ethnic category with the most beneficial outcomes for identity. For instance, to identify as BSA and thereby run the risk of locating the self within negative social representations of Islam in an Islamophobic social context would be likely to result in threats to the self-esteem principle of identity. It is difficult to enhance a positive conception of oneself on the basis of one's membership in a stigmatised group, which illustrates how self-esteem might be threatened (Gecas, 1982; Jaspal, 2011). Conversely, self-identification as Hindu or as Sikh might constitute a strategy for enhancing self-esteem since this category would position the individual outside of the potentially stigmatised ethno-religious category Muslim. Thus, strategic ethnic selfcategorisation possibly constitutes one strategy of maintaining and enhancing self-esteem (Heine et al., 2001; Muramoto, 2003), as highlighted in hypothesis 8:

Hypothesis 8: Individuals will utilise the socio-psychological resources (e.g. selfidentification as 'Hindu' rather than 'Asian') available to them to construe their ethnic identity in ways that safeguard the self-esteem principle.

The concept of the 'relational self' may be employed in order to explore how BSAs' contact with their 'ancestral homeland' can impact ethnic identity construction. BSA generally maintain close cultural links with their ancestral homeland, which is said to play a role in the strengthening of ethnic identity among the first and second generations alike (Jayaram, 1998). It has been convincingly argued that the origins of ethnicity among South Asians can only be fully understood through a detailed exploration of their migratory histories and contacts with the ancestral homeland (Brah, 1996; Ramji, 2003, 2006). On the other hand, it has also been highlighted that second generation BSAs' visits to their parents' ancestral homelands can act powerfully 'as instruments for accentuating not the Indianness of their ethnicities but their Britishness' (Harris, 2006, p. 143). This has been attributed to their inadequate linguistic skills abroad and to their distaste of 'third world' material living conditions (Harris, 2006). Moreover, BSA may emphasise their Britishness in the homeland context in order to enhance the distinctiveness principle of identity, since this constitutes one method of acquiring 'a sense of positive distinctiveness' from the dominant majority in the homeland context (Jaspal \& Coyle, 2009, p. 155). This is hypothesis 9:

Hypothesis 9: Individuals will utilise the socio-psychological resources (e.g. selfidentification in national rather than ethnic terms) available to them to construe ethnic identity in ways that ensure a positive sense of distinctiveness. 
Hypothesis 9 is consistent with a wealth of socio-psychological research, which suggests that individuals actively seek positive distinctiveness rather than distinctiveness in general (Campbell, 1986; Taylor \& Brown, 1988; Vignoles et al., 2000). This has generally been attributed to the fundamental need for self-esteem, particularly in research within the social identity paradigm (Abrams \& Hogg, 1988; Tajfel \& Turner, 1986). However, IPT regards all of the motivational principles are making unique contributions to the identity structure rather than as enhancing self-esteem as a 'superordinate' principle (Vignoles et al., 2000, 2002). Consequently, it is likely that the individual will seek to defend and enhance identity by safeguarding the operation of identity processes in accordance with as many principles as possible within a given social context, distinctiveness and self-esteem alike.

The above-cited studies lend empirical support to the importance of the 'relational self' in ethnic identity construction. It is through personal self-positioning within the homeland context that individuals come to perceive the existence of ethno-cultural differences underlying relations with Indians and Pakistanis in the Subcontinent, that is, they perceive themselves as ethnically distinctive from 'them'. Upon perceiving inter-ethnic differences, attempts are made to maintain and uphold ethnic boundaries, which determine ethnic ingroup membership.

\section{'Policing' ethnic boundaries - inclusion and exclusion}

There can be strong social pressure for ethnic group members to adhere to certain norms of behaviour, to acknowledge, to accept and to reproduce hegemonic social representations associated with the ethnic identity (Breakwell, 1988; Moscovici, 1988), and to possess selfaspects which are collectively believed to reflect one's 'ethnic authenticity' (Jaspal \& Coyle, $2009,2010 \mathrm{~b}$ ). The criteria for inclusion in the ethnic ingroup, the bases for exclusion, and the norms, values and social representations associated with the ethnic identity are socially constructed. Ethnic groups will form and disseminate social representations concerning ethnic identity in accordance with temporal and contextual factors. For example, although the Kamasutra constitutes an integral part of Indian cultural and religious history, representations concerning the position of the Kamasutra within Indian ethno-cultural and Hindu religious identity have become latent as ethno-cultural norms within Indian culture have become conservative over time (Puri, 2002). This particular example makes sense when regarded within the broader context of identity processes. It could be difficult to assimilate and accommodate social representations of Kamasutra, a sexually explicit aspect of Indian culture and the Hindu religion, within an identity structure, which has long internalised representations of Indian culture and the Hindu religion as culturally conservative concerning issues of sexuality (Puri, 2002). Attempts to do so could potentially jeopardise the psychological coherence principle of identity. Thus, individuals who reproduce representations of the Kamasutra might be 'otherised' by other members of their (Indian) ethnic group, given that the ethnic group may regard these representations as threatening for the integrity of ethnic identity.

Social representations of ethnic identity surface in accounts of how ethnic identity may be 'policed' by group members. For instance, in her study of US South Asians, Maira (2002, p. 14) suggests that individuals use certain markers of ethnic authenticity 'in order to contest one another's performances and narrations of ethnicity and to assert their own'. This essentially means that some self-aspects come to be perceived by group members as fundamental for ethnic group membership and that the perceived failure to possess these selfaspects provides sufficient socio-psychological grounds for the exclusion of non-conforming individuals from the ethnic group. Indeed, this notion is observable in research into the role of language in the construction of ethnic and religious identities. Jaspal and Coyle (2009, 2010a, 2010b) demonstrate that participants reproduced representations of "ethnic 
authenticity' by emphasising the importance of the heritage language as a marker of ethnic identity. The acceptance and reproduction of this social representation enabled individuals to affirm their own membership in the ethnic group, given that they claimed to possess the crucial self-aspect for inclusion in the group (i.e. knowledge of the heritage language). This had positive implications for identity since self-inclusion in the ethnic ingroup was said to enhance the belonging principle of identity. These individuals met their own constructed 'criteria' for inclusion and acceptance in the ingroup. This leads us to hypothesis 10:

Hypothesis 10: Ethnic group members will accentuate the importance of ethnic self-aspects which they perceive themselves to possess in order to enhance the belonging principle of identity.

Conversely, the constructed 'criteria' enabled individuals to question the ethnic authenticity of those who were perceived to lack knowledge of the heritage language; this led to the exclusion and 'otherisation' of non-conforming individuals. Indeed, for these individuals, the repudiation of one's ethnic identity (by ethnic ingroup members) can result in threats to the belonging principle, as alluded to in hypothesis 10. However, this may also have adverse consequences for the continuity principle, since this constitutes incoming information which is inconsistent with existing self-perceptions and personal representations (Breakwell, 1986). Jaspal and Coyle $(2009,2010 b)$ have identified some of the negative outcomes for psychosocial well-being (such as shame) as a result of perceived otherisation in this way. The social constructedness of such rhetorical defences of ethnic identity becomes evident when one considers that some participants rejected social representations linking the heritage language and ethnic authenticity but, nonetheless, laid claim to this ethnic identity. Crosscultural comparisons demonstrate the fundamentally ideological nature of how ethnic boundaries are policed. According to Jewish ideology, for instance, anybody with a Jewish mother is perceived to be a Jew, while in North Indian cultures it is the father's ethnic identity which is passed onto the child (see also Eriksen, 1993).

The socio-psychological effects of 'policing' ethnic boundaries or 'gatekeeping' may be considerable (Eriksen, 1993). One possibility is that some individuals may come to reject aspects of their ethnic identities, possibly resulting in complete disidentification. Indeed psychologists have identified and described the strategy of self-removal from positions which pose potential threats to identity (Breakwell, 1986; Vugt \& Hart, 2004). For instance, in a study exploring how Greek Cypriot gay men manage their ethnic and sexual identities, individuals were said to disidentify with their ethnic group due to the negative social representations of homosexuality operating in Greek Cypriot cultural contexts (Phellas, 2005). The same psychological process is observable in studies of ethnic and religious identities among British Muslims. In her interview study with British Pakistanis, Jacobson (1997) noted that some participants seemed to denigrate their ethnic identity and to attach more positive value to their religious identities (see also Jaspal \& Cinnirella, 2010a). This was attributed to the social representation that their ethnic culture was associated with 'traditional and tradition-bounded cultures of parents' (Jacobson, 1997, p. 245), which was perceived by some participants as becoming increasingly distant from Islamic norms and values (see also Kibria, 2008). Accordingly, it could be hypothesised that:

Hypothesis 11: Individuals who themselves lack self-aspects which they nonetheless perceive to be fundamental for inclusion in the ethnic group will denigrate the importance of ethnic identity in their self-concept as a strategy for coping with potential threat to belonging. 
In essence, hypothesis 11 reflects a synthesis of the re-evaluation and re-construal coping strategies identified in IPT (Breakwell, 1986). The psychological strategy of self-removal from one's ethnic group because group members do not feel that they conform to the norms, values and self-aspects associated with the ethnic group may be justified rhetorically by denigrating the ethnic identity or by downgrading its importance vis-à-vis another competing identity. Among BSA who self-identify as Muslim, religious identity is likely to constitute a preferable alternative to ethnic identity given that self-identification in religious terms may induce a perceived transnational connection with the Islamic 'Umma' or global Muslim community (Jacobson, 1997; Kibria, 2008).

However, the 'exit option' may not always constitute a desirable psychosocial response to 'gatekeeping'. Social representations of ethnic boundaries may be re-construed by individuals (Breakwell, 2001). As noted, Jaspal and Coyle (2010b) found that some group members exhibited awareness of the social representation linking the heritage language and ethnic identity but that they did not accept and reproduce this representation themselves. Instead some non-speakers of their heritage language distanced themselves psychologically from the linguistic dimension of their ethnic identity by downgrading the importance of the heritage language in ethnic identity. Furthermore, individuals re-conceptualised social representations concerning ethnic boundaries by construing themselves (i.e. non-speakers of their heritage language) as normative, prototypical ethnic ingroup members and, conversely, by construing speakers of their heritage language as atypical group members. These individuals engaged in the coping strategy of re-conceptualising existing criteria for ethnic group membership, which is described in IPT. This process is reflected in hypothesis 12:

Hypothesis 12: When social representations are sufficiently malleable so as to facilitate re-construal (Jaspal \& Coyle, 2009), individuals who lack self-aspects associated with their ethnic identity will re-conceptualise the criteria for inclusion in the ingroup in order to enhance the belonging principle of identity.

Hypothesis 12 is consistent with Breakwell's (1986) intrapsychic strategy of re-construal, although it further refines this by explicitly acknowledging 'the social representational constraints on identity processes' (Breakwell, 2001). Notions of policing ethnic boundaries and ethnic 'gatekeeping', which could result in the repudiation of membership in the ethnic group, illustrate the bi-dimensionality of ethnicity. One's own sense of ethnic identity may not necessarily coincide with the ethnic identity category 'ascribed' by ingroup and outgroup members (Phinney et al., 2001). For instance, as discussed above, Jaspal and Coyle (2009) have found that BSA who do not speak their heritage language may nonetheless lay claim to a South Asian ethnic identity, although their ethnic identity may be repudiated by South Asians who identify the heritage language as a mandatory self-aspect of South Asian ethnic identity. On the other hand, one might present oneself as a member of an ethnic group with which one does not actually identify. In her discussion of interpersonal strategies for coping with threats to identity, Breakwell (1986, p. 116) refers to the notion of passing, whereby one gains 'access to a group or social category (sexual, racial, political, economic or religious) by camouflaging one's group origins'. For instance, in a study on language stigma among Andalusians, Jaspal and Sitaridou (2010) noted that some speakers of Andalusian Spanish engaged in the strategy of passing in order to present themselves as speakers of Standard Spanish. More specifically, they concealed their Andalusian ethno-national identity in order to avoid the identity-threatening stigma associated with membership in their original group. Thus, in contrast to the examples of Islamic revivalism provided above, a Muslim of Pakistani background might, for instance, camouflage and conceal their Pakistani ethnic identity and instead lay claim to the superordinate ethnic identity South Asian in order to 
avoid potential discrimination and 'otherisation' in an Islamophobic social context, as highlighted in hypothesis 13:

\begin{abstract}
Hypothesis 13: When two or more ethnic identity categories are perceived as being available to an individual, the identity category evoking the most positive social representations will be selected for ethnic self-categorisation. This strategy of positive self-presentation will be preferred specifically in interpersonal encounters (particularly with ethnic outgroup members) and will enhance selfesteem (see Jones et al., 1981).
\end{abstract}

Crucially, the preferred ethnic category need not necessarily be a superordinate one (cf. Gaertner \& Dovidio, 2000) as exemplified by the aforementioned study on Andalusian Spaniards. The potential flexibility associated with ethnic self-categorisation and the resourcefulness of social actors in enhancing identity processes by identifying in specific ways is succinctly demonstrated in hyphenated and hybridised modes of self-identification.

\title{
Hyphenated ethnic identity and the emergence of 'new ethnicities'
}

Debate surrounding the compatibility of ethnic, religious and national identities among ethnic minority members in the West permeate the media (Archer, 2009; Werbner, 2000), and dominant social representations of ethnic minority members' identity configurations generally suggest that these identities are difficult to reconcile (Richardson, 2004; van Dijk, 1991). In the past this led some scholars to highlight the centrality of 'culture conflict' and 'identity conflict' in the BSA experience; BSA were generally discussed as living between cultures rather than in either or both of them (e.g. Anwar, 1976, 1986; Watson, 1977). However, more recently, social scientists have rejected claims of 'identity conflict' among BSA whereby these individuals are depicted as being 'stuck between two cultures' (Ghuman, 2003; Harris, 2006). Although there is growing recognition of the potentially beneficial aspects of dual identification, such as the ability to adapt to two different ethno-cultural groups (Hutnik \& Bhola, 1994; LaFramboise et al., 1993), there remains the question of how multiple, and potentially conflictual, identities are actually managed in everyday life (Amiot et al., 2007; Verkuyten, 2005). As Verkuyten (2005, p. 179) observes, 'multiple identities may also imply a kind of rivalry or psychological conflict between different understandings and loyalties'. IPT proposes that individuals will actively strive to construe identities, which individuals regard as being inter-connected within the self-concept, as compatible and coherent (Jaspal \& Cinnirella, 2010a). Psychological coherence is 'achieved' when the individual ceases to perceive conflict or incompatibility between their inter-connected identities.

There have been a number of alternative approaches to identity management. For instance, Ballard (1994) describes 'code-switching' practices among BSA who are said to manage their multiple identities by switching between them in distinct social contexts just as a bilingual code-switcher might switch between linguistic codes in a single interaction. The notion of code-switching echoes the well-known statement that 'one can be Muslim in the Mosque, Asian in the street, Asian British at political hustlings and British when travelling abroad, all in a single day' (Cohen, 2000, p. 582). The underlying assumption is that identities are fluid, negotiated and compartmentalised according to social context. However, this approach ignores the increasingly convincing thesis that identities may in fact be mixed and inextricably entwined (see Jaspal \& Cinnirella, 2010a).

This echoes the notion of compartmentalisation, which has been identified by social psychologists as a strategy for managing multiple (and potentially conflictual) identities (Breakwell, 1986; Roccas \& Brewer, 2002). IPT describes this as a potential strategy for 
averting or curtailing identity threat, possibly as its deployment impedes the intrapsychic conflict associated with incompatible identities (Baumeister, 1986; Harter \& Monsour, 1992). Although this is likely to constitute an effective short-term strategy for optimising multiple identification, there is empirical evidence to suggest that there may be some contexts in which the compartmentalised identities will enter into contact, thereby problematising the efficacy of the compartmentalisation strategy (Jaspal \& Cinnirella, 2010a). It is partly this dissatisfaction with the notion of compartmentalisation which has sensitised scholars to the heuristic value in post-structural approaches to ethnic identity. These forward the argument that multiple identities are reconciled by social actors rather than rigidly compartmentalised according to the social context.

Terms such as 'hyphenated identities', 'hybridity' and 'creolisation', which 'draw attention to cases where various meanings and identities converge or are blended, thereby forming new ways of being', have begun to gain ground in social research into second generation immigrants in particular (Verkuyten, 2005, p. 150). These approaches challenge existing category conceptions and ways of thinking about ethnic identity construction. Here it is argued that IPT is very well-suited to provide insight into the motivational principles underlying the construction of complex multifaceted ethnic identities (cf. Verkuyten, 2005).

Ghuman (2003) highlights that many BSA youths tend to employ various different hyphenated identity categories in order to describe their ethno-national identities; those of Pakistani descent often juxtapose the national component of self with religious identity (i.e. British Muslim) and those of Indian descent frequently combine their national and ethnic identities (i.e. British Indian). Hutnik and Street (2010) observe that a large division within their participant sample was rooted in both ethnic and national identities, highlighting their hyphenated identities. By laying claim to hyphenated identities BSA may be able to reconcile their multiple identities in an ethno-national identity category which suggests coherence and compatibility; this is likely to benefit psychological coherence:

Hypothesis 14: Hyphenated ethnic self-categorisation will enhance the psychological coherence principle of identity among second and third generation immigrants.

Since it is likely that many BSA regard their ethno-religious and national identities as conflictual and contradictory as a result of dominant social representations regarding these identity configurations (Phillips, 2006), pervasive use of hyphenated identities may encourage social representations of compatibility and coherence of the two or more identities. The personalisation of such representations by BSA themselves might influence their own perceptions of compatibility and coherence between these inter-connected identities.

Although hyphenation has been discussed positively in the social sciences literature, there is some evidence that the socio-psychological implications of self-identification in this way may be problematic. For instance, Abbas $(2000,2002)$ has found that identity hyphenation may be perceived negatively by first generation BSA who may hold the social representation that their children, the second generation, are becoming increasingly distant from self-aspects associated with their ethno-cultural and religious identities. One peripheral aspect of this representation may be that the ethnic group identity is perceived by the first generation as lacking social status among the second generation. While the second generation might identify in this way in order to safeguard psychological coherence, the first generation may in fact construe this identificatory tendency as threatening for the continuity principle of their identities: 
Hypothesis 15: Hyphenated ethnic self-categorisation among second generation BSA will pose threats to the continuity principle of identity among those first generation BSA who identify their ethnic identity as 'core'.

Abbas' $(2000,2002)$ work suggests that first generation BSA perceive the continuity of their ethnic identity to be threatened because hyphenation represents a degree of psychological rapprochement with the ethnic outgroup (i.e. the White British majority). This may be construed by social actors as negative social change. Hyphenation can have varying implications for identity processes among first and second generation BSA. Verkuyten (2005) has noted that for the first generation, use of singular ethnic categories (e.g. Indian, Pakistani) for self-definition are common, which itself may constitute a means of enhancing continuity across time, although later generations may reject singular categories. Future research should explore how first and second generation BSA reconcile the opposing motivational principles associated with their identities and which ones they perceive to be associated with the notion of hyphenation. This matter is a multifaceted and complex one, since it concerns identity integration at the intrapsychic level, as well as a potential interpersonal conflict between the first and second generations to protect and enhance distinct motivational principles associated with their own identities.

In addition to hyphenation, the related concepts of 'hybridity' and 'new ethnicities' have been employed by social scientists to indicate how (ethnic) elements, meanings and forms are mixed and blended in order to give rise to new ethnic modes; new ethnic modes are said to be created through the juxtaposition of old ones (Hall, 2002; Harris, 2006; Werbner, 1997). In research on ethnicity, these terms have been employed in order to deconstruct notions of essentialism and ethnic boundaries and to valorise arguments of mixed, non-static and fluid ethnic identities. Within the context of BSA, 'new ethnicities' have been described as retaining some characteristics of traditions derived from the Indian Subcontinent as well as being shaped by an 'everyday low-key Britishness, albeit a Britishness with new inflections' (Harris, 2006, p. 1; italics added). Crucially, the notion that new inflections underlie the "new ethnicities' of second generation BSA has implications for ethnic categorisation. It is perhaps the emphasis upon new inflections which leads Harris to reject common hyphenated categories such as British Asian which for him 'continues an entrenched mindset which envisages two entirely separate strongly bound and homogeneous cultures' (p. 1).

Accordingly, there are no longer discrete, homogeneous cultures which individuals negotiate by manoeuvring from one to the other, but rather a new ethnicity in which 'at any given moment both British and particular South Asian derived elements are always copresent' (Harris, 2006, p. 1-2). Harris (2006) proposes the ethnic category 'Brasian' as a more appropriate alternative to British Asian since this reflects the fusion of British and Asian cultural self-aspects and, thus, exhibits the 'openness, variability and unpredictability' of second generation identities. While social scientists have introduced interesting new constructs such as hyphenation, which suggest greater integration of existing, and potentially conflictual, social identities, there has been relatively little insight into how these identities are actually managed and reconciled by individuals themselves (Verkuyten, 2005). Scholarly inquiry into these issues is important as these identificatory patterns are likely to have wideranging implications for the identity principles. By laying claim to a hybrid ethnic identity, second generation BSA perhaps acquire a sense of ethnic distinctiveness from first generation BSA who may oppose their hybrid ethnic identities (Abbas, 2000, 2002).

Hypothesis 16: Hybrid ethnic self-categorisation will enhance the distinctiveness principle of identity among second and third generation BSA in socio- 
psychological contexts in which they are in contact with 'indigenous' members of their ethnic group (non-BSA).

By highlighting their distinctiveness from 'indigenous' members of the ethnic group, BSA may be able to develop a sense of positive distinctiveness. This sense of distinctiveness is strengthened by subjective observations that life in Britain is qualitatively superior to life in the Subcontinent (Harris, 2006).

It is possible that hybrid self-categorisation will have positive implications for psychological coherence. In articulating 'a Britishness with new inflections' (from their ethno-religious identities) BSA are perhaps able to fulfil the "need for compatibility and coherence between pre-existing [ethnic and national] identities - i.e., between different constituent elements of the self-concept' (Jaspal \& Cinnirella, 2010a, p. 865).

Hypothesis 17: Like hyphenated ethnic self-categorisation, hybrid selfcategorisation will enhance the psychological coherence principle of identity among second and third generation immigrants.

The concept of new ethnicities suggests that this is no longer a case of reconciling two or more potentially conflictual identities but rather that these identities have already been reconciled in a coherent and compatible sense of self. Crucially, perceived distinctiveness from other members of their ethnic group (i.e. first generation; South Asians in the Subcontinent) is likely to enhance individuals' perception that their mode of 'being' is unique and distinct. Thus, their distinctiveness lies in their construction of unique hybrid identities, which are composed of national and ethnic elements. Moreover, the category 'Brasian' suggests that there is no 'dominant' or psychologically salient identity, which must be prioritised and 'hierarchised', but rather a fluid 'new ethnicity' in which the two identities are subjectively perceived as constituting a new unitary identity. While dominant social representations might dictate that ethnic and national identities are qualitatively discrete, the individual will perceive them as being entwined and inseparable, signalling a high level of coherence. Crucially, as Jaspal and Cinnirella (2010a, p. 866) point out, "psychological coherence is in the eye of the perceiver and not some objective quality of the identities under scrutiny'. Thus, the extent to which individuals subjectively perceive their interconnected identities as coherent and compatible is of crucial importance in assessing psychological coherence.

\section{Conclusions}

The present paper demonstrates some of the ways in which socio-psychological theorising on identity processes may be connected and reconciled with the broader social sciences literature on ethnicity. In particular, this paper demonstrates ways in which patterns of ethnic identity functioning may be explained by the motivational principles of identity forwarded by IPT. Some suggestions are provided regarding the socio-psychological conditions under which one form of ethnic identity expression rather than another will occur. Moreover, IPT provides the researcher with the heuristic tools to explain why subgroups within an ethnic group (e.g. second or third generation immigrants) might favour some forms of ethnic expression rather than others.

The centrality of the 'relational self' in ethnic identity formation, which is forwarded primarily by anthropologists, may be explained by the principle of (intergroup) distinctiveness. Moreover, given that racism and discrimination can form part of BSAs' life narratives (Modood et al., 1997), it is likely that identification with the ethnic group may salvage belonging. This identificatory strategy may endow BSA with a sense of acceptance 
and belonging, which is susceptible to threat as a result of their perceived exclusion from the category British. Processes of hybrid self-categorisation, which are firmly associated with anthropological and sociological approaches to ethnicity, are likely to enhance psychological coherence. This seems a plausible assumption since hybrid identities may allow individuals the flexibility of not having to commit themselves to self-aspects and social representations associated with any one identity, although it is acknowledged that this will depend largely upon how hegemonic these representations are (Breakwell, 2001). Rather, hybrid selfcategorisation can enable individuals to re-construe social representations and to select strategically those self-aspects, which are perceived as reflecting their 'new ethnicities'. Crucially, this does not compel individuals to choose between their identities but instead allows them to reconcile them in a coherent and compatible sense of self (Jaspal \& Cinnirella, 2010a).

It is suggested that merely perceiving a sense of continuity or distinctiveness is unlikely to be sufficient for the development of a positive ethnic identity. Rather these principles must be positively construed. For instance, it is necessary to feel positively distinctive from relevant ethnic outgroups (Tajfel, 1981). This point is inextricably connected with the notion of social change, since social representations may be created or reactivated subsequent to social events. Accordingly, identification with particular ethnic groups or self-categorisation in specific ways will affect the principled operation of identity processes to varying degrees. It has been argued that the ethnic category South Asian may be adopted or eschewed in order to enhance continuity and self-esteem. Moreover, this may explain why ethnic boundaries are constructed and 'policed' in particular ways; the 'otherisation' of individuals perceived to lack a given self-aspect may in fact enhance the identity of individuals who indeed possess the self-aspect. Consequently, researchers should differentiate between potentially inter-connected identity categories (e.g. ethnic, religious) in order to understand motivations underlying ethnic self-categorisation (Jaspal, in press).

Turning to methodological issues, the hypotheses presented here exhibit the need for some methodological flexibility in research into ethnic identity construction. Generalisable predictions elucidating the conditions under which one form of ethnic identity expression rather than another will occur require quantitative (e.g. experimental, correlational) approaches to research on ethnic identity construction (Zagefka, 2009). Similarly, there is clearly much heuristic value in qualitative (e.g. discursive and rhetorical) approaches to ethnic identity. In-depth interviews would likely elucidate the nature of the largely rhetorical 'facts' which are provided by group members in order to validate ethnic identity as well as the subtle rhetorical strategies employed in highlighting the positive aspects (and in downgrading the negative aspects) of the ingroup's history. Methodologies which also encompass the study of societal social representations (e.g. in mass media) of ethnicity are valuable, since such social representations provide a backdrop for the intra-psychic level of analysis that should not be ignored. Thus, methodological pluralism is encouraged and indeed a necessary strategy if the IPT approach to ethnic identity is to be fully exploited. While some researchers would argue for irreconcilable epistemological incompatibilities between some of these methods, we, instead, adopt a more eclectic stance, as for example, evinced by researchers interested in social representations, who have tended to embrace the triangulation philosophy we forward here (see, for example, Breakwell \& Canter, 1993).

In this paper, we have striven to demonstrate the heuristic value of IPT in ethnic studies through an exploration of the substantive literature on ethnic identity construction among BSA, with some reference to other populations. In conclusion, it is argued that through the interpretive lens of IPT researchers will be better positioned to understand the socio-psychological aspects of ethnic identity construction, ethnic self- and othercategorisation and inter-ethnic behaviour. Given the major credentials of IPT, which have 
been highlighted in this paper, future empirical work should employ the theory to explore, multi-methodologically, the construction of ethnic identity among BSA and other populations.

\section{References}

Abbas, T. (2000) How South Asians achieve in education: a comparative study of Bangladeshis, Indians and Pakistanis in Birmingham schools and colleges. Unpublished $\mathrm{PhD}$ thesis, University of Warwick.

Abbas, T. (2002) 'Teacher perceptions of South Asians in Birmingham schools and colleges', Oxford Review of Education 28(4): 447-71.

Abizadeh, A. (2001) 'Ethnicity, race, and a possible humanity', World Order, 33(1): 23-34.

Abrams, D., \& Hogg, M. A. (1988) 'Comments on the motivational status of self-esteem in social identity and intergroup discrimination', European Journal of Social Psychology, 18: 317-334.

Amiot, C.E., de la Sablonnière, R., Terry, D.J. \& Smith, J.R. (2007) 'Integration of social identities in the self: toward a cognitive-developmental model', Personality and Social Psychology Review 11: 364-88.

Anwar, M. (1976) Between Two Cultures. London: Community Relations Commission.

Anwar, M. (1986) 'Young Asians between two cultures', in V. Coombe \& A. Little (eds.), Race and Social Work, pp. 50-58. London: Routledge.

Anwar, M. (1998) Between Cultures: Continuity and Change in the Lives of Young Asians. London: Routledge.

Archer, L. (2009) 'Race, 'face' and masculinity: the identities and local geographies of Muslim boys', in P. Hopkins \& R. Gale (eds.), Muslims in Britain: Race, Place and Identities. Edinburgh: Edinburgh University Press.

Balibar, E. \& Wallerstein, I. (1991) Race, nation, class. London: Verso.

Ballard, R. (1994). 'Introduction: The emergence of Desh Pardesh', in R. Ballard (Ed.), Desh Pardesh: The South Asian Experience in Britain, pp. 1-35. London: C. Hurst \& Co.

Bar-Tal, D. \& Teichman, Y. (2005) Stereotypes and prejudice in conflict: representations of Arabs in Israeli Jewish society. Cambridge: Cambridge University Press.

Baumeister, R.F. (1986). Identity: cultural change and the struggle for self. Oxford: Oxford University Press.

Baumeister, R. F. \& Leary, M. R. (1995) 'The need to belong: desire for interpersonal attachments as a fundamental human motivation', Psychological Bulletin, 117: 497529.

Brah, A. (1996) Cartographies of diaspora: contesting identities. London: Routledge.

Breakwell, G.M. (1986) Coping with threatened identities. London: Methuen.

Breakwell, G.M. (1992) 'Processes of self-evaluation: efficacy and estrangement', in G.M.

Breakwell (Ed.), Social psychology of identity and the self concept, pp. 35-55.

London: Academic Press/Surrey University Press.

Breakwell, G.M. (1996) 'Identity processes and social changes', in G.M Breakwell \& E. Lyons (eds.), Changing European Identities: Socio-psychological Analyses of Social Change, pp. 13-30. Oxford: Butterworth-Heinemann.

Breakwell, G.M. (2001) 'Social representational constraints upon identity processes', in K. Deaux \& G. Philogène (eds.), Representions of the social: bridging theoretical traditions, pp. 271-284. Oxford: Blackwell.

Breakwell, G.M. \& Canter, D. (1993) Empirical Approaches to Social Representations. Oxford: Oxford University Press.

Brewer, M.B. (1991) 'The social self: on being the same and different at the same time', Personality and Social Psychology Bulletin 17: 475-482. 
Brown, R. (2000) 'Social identity theory: past achievements, current problems and future challenges', European Journal of Social Psychology 30: 745-778.

Campbell, J. D. (1986) 'Similarity and uniqueness: the effects of attribute type, relevance, and individual differences in self-esteem and depression', Journal of Personality and Social Psychology 50: 281-294.

Cinnirella (1997) 'Ethnic and national stereotypes: a social identity perspective', in C.C. Barfoot (Ed.), Beyond Pug's Tour: National and ethnic stereotyping in theory and literary practice, pp. 253-274. Amsterdam: Editions Rodopi.

Cinnirella, M. (1998) 'Exploring temporal aspects of social identity: the concept of possible social identities', European Journal of Social Psychology 28: 227-248.

Cohen, R. (2000) 'The incredible vagueness of being British/English (review article)', International Affairs 76(3): 575-582.

Cohen, S. (2001) States of denial: Knowing about atrocities and suffering. Cambridge: Polity Press.

Deaux, K. (1993) 'Reconstructing social identity', Personality and Social Psychology Bulletin 19(1): 4-12.

De Vos, G.A. (1995) 'Ethnic pluralism: conflict and accommodation', in L. Romanucci-Ross \& G. De Vos (Eds.), Ethnic identity: Creation, Conflict and Accommodation, pp. 1547. Walnut Creek, CA: Alta Mira.

Doob, L. (1964) Patriotism and nationalism: their Psychological Foundations, New Haven: Yale University Press.

Eriksen, T.H. (1993) Ethnicity and Nationalism: Anthropological Perspectives. London: Pluto Press.

Eriksen, T.H. (2001) 'Ethnic identity, national identity and intergroup conflict: the significance of personal experiences', in R.D. Ashmore, L. Jussim \& D. Wilder (eds.), Social identity, intergroup conflict and conflict reduction, pp. 42-70. Oxford: Oxford University Press.

Gaertner, S.L. \& Dovidio, J.F. (2000) Reducing intergroup bias: the common ingroup identity model. Philadelphia, USA: Psychology Press.

Gecas, V. (1982). 'The self-concept', Annual Review of Sociology 8: 1-33.

Geertz, C. (1973). Interpretations of cultures. New York: Basic Books.

Ghuman, P.A.S. (2003). Double Loyalties: South Asian Adolescents in the West. Cardiff: University of Wales Press.

Ghuman, P.A.S. (2005) 'Daughters of tradition', The Psychologist, 18(10): 620-22.

Hall, D.K. (2002) Lives in Translation: Sikh Youths as British Citizens. Philadelphia: University of Pennsylvania Press.

Harris, R. (2006) New Ethnicities and Language Use. Basingstoke: Palgrave Macmillan.

Harter, S. \& Monsour, A. (1992) 'Developmental analysis of conflict caused by opposing attributes in the adolescent self-portrait', Developmental Psychology, 28: 251-260.

Heine, S. J., Kitayama, S., Lehman, D. R., Takata, T., Ide, E., Leung, C. \& Matsumoto, H. (2001) 'Divergent consequences of success and failure in Japan and North America: An investigation of self-improving motivations and malleable selves', Journal of Personality and Social Psychology, 81: 599-615.

Hofman, J.E. (1988) 'Social identity and intergroup conflict: an Israeli view', in W. Stroebe, A.W. Kruglanski, D. Bar-Tal \& M. Hewstone (Eds.), The Social Psychology of Intergroup Conflict, pp. 80-102. New York: Springer Verlag.

Hopkins, P.E. (2004) 'Young Muslim men in Scotland: inclusions and exclusions', Children's Geographies 2(2): 257-72.

Hutnik, N. \& Bhola, P. (1994) Self-categorisation and responses to threat, paper presented to the VIth International Conference on Language and Social Psychology, Brisbane, 
Australia, July.

Hutnik, N. \& Street, R.C. (2010) 'Profiles of British Muslim Identity: Adolescent Girls in Birmingham', Journal of Adolescence 33: 33-42.

Jacobson, J. (1997) 'Religion and ethnicity: Dual and alternative sources of identity among young British Pakistanis', Ethnic and Racial Studies 20(2): 238-256.

Jaspal, R. (in press) 'Delineating ethnic and religious identities in research with British South Asians', Psychological Studies.

Jaspal, R. (2011) 'Caste, social stigma and identity processes', Psychology and Developing Societies, 23(2): 27-62.

Jaspal, R. \& Cinnirella, M. (in press) 'Identity processes, threat and interpersonal relations: accounts from British Muslim gay men', Journal of Homosexuality.

Jaspal, R. \& Cinnirella, M. (2010a) 'Coping with potentially incompatible identities: accounts of religious, ethnic and sexual identities from British Pakistani men who identify as Muslim and gay', British Journal of Social Psychology 49(4): 849-70.

Jaspal, R. \& Cinnirella, M. (2010b) 'Media representations of British Muslims and hybridised threats to identity', Contemporary Islam: Dynamics of Muslim Life 4(3): 289-310.

Jaspal, R. \& Coyle, A. (2009) 'Language and perceptions of identity threat', Psychology and Society 2(2): 150-167.

Jaspal, R. \& Coyle, A. (2010a) "Arabic is the language of the Muslims - that's how it was supposed to be': exploring language and religious identity through reflective accounts from young British-born South Asians', Mental Health, Religion and Culture 13(1): 17-36.

Jaspal, R. \& Coyle, A. (2010b) 'My language, my people': language and ethnic identity among British-born South Asians', South Asian Diaspora 2(2): 201-18.

Jaspal, R. \& Sitaridou, I. (2010) Coping with stigmatised linguistic identities: a synthesis of identity process theory and ethnolinguistic vitality, paper presented to the British Psychological Society Social Psychology Section Annual Conference, University of Winchester, UK, September.

Jayaram, N. (1998) 'Social construction of the Other Indian: Encounters between Indian Nationals and Diasporic Indians', Journal of Social and Economic Development 1(1): 46-63.

Jones, E. E., Rhodewalt, F., Berglas, S. \& Skelton, J.A. (1981) 'Effects of strategic selfpresentation on subsequent self-esteem', Journal of Personality and Social Psychology 41(3): 407-421.

Kalkman, B. (2003) Personal meaning among Indo-Canadians and South Asians. Unpublished $\mathrm{PhD}$ dissertation, Trinity Western University.

Kibria, N. (2008) 'The new Islam and Bangladeshi youth in Britain and the U.S', Ethnic and Racial Studies 31(2): 243-266.

LaFramboise, T., Coleman, H. \& Gerton, J. (1993) 'Psychological impact of biculturalism: evidence and theory', Psychological Bulletin 114: 395-412.

Lyons, E. (1996) 'Coping with social change: processes of social memory in the reconstruction of identities', in G.M. Breakwell \& E. Lyons (eds.), Changing European identities: socio-psychological analyses of social change, pp. 31-40. Oxford: Butterworth-Heinemann.

Maira, S. M. (2002) Desis in the House: Indian American Youth Culture in New York City. Philadelphia: Temple University Press.

Mason, D. (2000) 'Ethnic Identity', in G. Payne (Ed.), Social Divisions, pp. 91-114. London: Macmillan. 
Modood, T., Beishon, S. \& Virdee, S. (1994) Changing Ethnic Identities. London: Policy Studies Institute.

Modood, T., Berthoud, R., Lakey, J., Nazroo, J., Smith, P., Virdee, S. \& Beishon, S. (1997) Ethnic Minorities in Britain: Diversity and Disadvantage. London: Policy Studies Institute.

Moscovici, S. (1988) 'Notes towards a description of social representations', European Journal of Social Psychology 18: 211-250.

Muramoto, Y. (2003) 'An indirect self-enhancement in relationships among Japanese', Journal of Cross-Cultural Psychology 34: 552-566.

Nash, M. (1989) The Cauldron of Ethnicity in the Modern World. Chicago: Chicago University Press.

Phellas, C.N. (2005) 'Cypriot gay men's accounts of negotiating cultural and sexual identity: a qualitative study', Qualitative Sociology Review 1(2): 65- 83.

Phillips, M. (2006) Londonistan. London: Gibson Square.

Phinney, J. S. (1996) 'When we talk about American ethnic groups, what do we mean?' American Psychologist 51: 918-927.

Phinney, J.S., Horenczyk, G., Liebkind, K. \& Vedder, P. (2001) 'Ethnic identity, immigration and well-being: An interactional perspective', Journal of Social Issues 57(3): 493510.

Phukon, G. (2002) 'Introduction', in G. Phukon (Ed.), Ethnicity and Polity in South Asia. New Delhi: Sage.

Puri, J. (2002) 'Concerning "Kamasutras": challenging narratives of history and sexuality', Signs: Journal of Women in Culture and Society 27(3): 603-39.

Raj, D. S. (1997) Shifting Culture in the Global Terrain: Cultural Identity Constructions Amongst British Punjabi Hindus. Unpublished PhD dissertation, University of Cambridge.

Raj. S.D. (2000) "“Who the hell do you think you are?"' Promoting religious identity among Young Hindus in Britain', Ethnic and Racial Studies 23(3): 535-58.

Ramji, H. (2003) 'Engendering diasporic identities', in N. Puwal \& P. Rughuram, (eds.), Critical Reflections on Gender and the South Asian Diaspora, pp. 227-42. Oxford: Berg.

Ramji, H. (2006) 'Journeys of difference: The use of migratory narratives among British Hindu Gujaratis', Ethnic and Racial Studies 29(4): 702-724.

Reicher, S. \& Hopkins, N. (2001) Self and Nation. London: Sage

Rex, J. (2004) 'Empire, race and ethnicity', International Journal of Comparative Sociology 45(3): 161-173.

Richardson, J.E. (2004) (Mis)representing Islam: The racism and rhetoric of British broadsheet newspapers. Amsterdam: John Benjamins.

Roberts, R.E., Phinney, J.S., Mass, L.C., Chen, Y.R., Roberts, C.R. \& Romero, A. (1999) 'The structure of ethnic identity of young adolescents from diverse ethnocultural Groups', Journal of Early Adolescence 19(3): 301-22.

Robinson, L. (2009) 'Cultural identity and acculturation preferences among South Asian adolescents in Britain: an exploratory study', Children and Society 23(6): 442-454.

Roccas, S. \& Brewer, M. B. (2002) 'Social identity complexity', Personality and Social Psychology Review 6: 88-106.

Scott, G.M. (1990) 'A resynthesis of the primordial and circumstantial approaches to ethnic group solidarity: towards an explanatory model', Ethnic and Racial Studies 13(2): 147-71.

Sheridan, L.P. (2006) 'Islamophobia pre- and post-September $11^{\text {th }} 2001$ ', Journal of Interpersonal Violence 21(3): 317-36. 
Smaje, C. (1997) 'Not just a social construct: theorising on race and ethnicity', Sociology 31(2): 307-27.

Smith, A. D. (1986) The ethnic origins of nations. Oxford: Blackwell.

Smith, A.D. (1991) National Identity, London: Penguin.

Smith, A. D. (1998) Nationalism and modernism. London: Routledge.

Speller, G.M. (2000) A community in transition: a longitudinal study of place attachment and identity processes in the context of an enforced relocation. Unpublished $\mathrm{PhD}$ dissertation, University of Surrey, Guildford, UK.

Sternberg, R. J., Grigorenko, E. L., \& Kidd, K. K. (2005) 'Intelligence, race, and genetics', American Psychologist 60: 46-59.

Tajfel, H. (1981) Human Groups and Social Categories. Cambridge: Cambridge University Press.

Tajfel, H., \& Turner, J. C. (1986) 'The social identity theory of intergroup behaviour', in S. Worchel, \& W. G. Austin (Eds), Psychology of intergroup relations, pp. 7-24. Chicago, IL: Nelson-Hall.

Taylor, S. E., \& Brown, J. D. (1988) 'Illusion and well-being: a socio-psychological perspective on mental health', Psychological Bulletin 103:193-210.

Tikoo, R. (2002) 'Ethnicity and politics in Pakistan', in G. Phukon (Ed.), Ethnicity and Polity in South Asia. New Delhi: Sage.

Timotijevic, L. (2000) Adaptive Processes of Identity - Identity Threats of Migration. Unpublished PhD dissertation, University of Surrey, UK.

Timotijevic, L. \& Breakwell, G.M. (2000) 'Migration and threat to identity', Journal of Community and Applied Social Psychology 10: 355-72.

Triandafyllidou, A. (2001) Immigrants and National Identity in Europe. London: Routledge.

Turner, J.C., Hogg, M.A., Oakes, P.J., Reicher, S.D. \& Wetherell, M. (1987) Rediscovering the social group: a self-categorization theory. Oxford: Blackwell.

Vadher, K. \& Barrett, M. (2009) 'Boundaries of British in British Indian and Pakistani young adults', Journal of Community and Applied Social Psychology 19 442-458.

Van Dijk, T.A. (1991) Racism and the Press. London: Routledge.

Verkuyten, M. (2005) The Social Psychology of Ethnic Identity. Hove: Psychology Press.

Verkuyten, M., van de Calseijde, S. \& De Leur, W. (1999) 'Third generation South Moluccans in the Netherlands: the nature of ethnic identity', International Journal of Ethnic and Migration Studies 25: 63-79.

Vignoles, V. L., Chryssochoou, X., \& Breakwell, G. M. (2000) 'The distinctiveness principle: identity, meaning and the bounds of cultural relativity' Personality and Social Psychology Review 4: 337-354.

Vignoles, V. L., Chryssochoou, X., \& Breakwell, G. M. (2002) 'Evaluating models of identity motivation: Self-esteem is not the whole story', Self and Identity 1: 201-218.

Vignoles, V.L., Regalia, C., Manzi, C., Golledge, J. \& Scabini, E. (2006) 'Beyond selfesteem: influence of multiple motives on identity construction', Journal of Personality and Social Psychology 90: 308-333.

Vugt, V.M. \& Hart, C.M. (2004). 'Social identity as social glue: The origins of group loyalty', Journal of Personality and Social Psychology 86: 585-598.

Watson, J. L. (1977). Between Two Cultures: Migrants and Minorities in Britain. Oxford: Blackwell.

Werbner, P. (1997). 'Introduction: the dialectics of cultural hybridity', in P. Werbner \& T. Modood (eds.), Debating cultural hybridity: multi-cultural identities and the politics of anti-racism, pp.1-26. London: Zed Books.

Werbner, P. (2000). 'Divided loyalties, empowered citizenship? Muslims in Britain', Citizenship Studies 4(3): 307-24. 
Wills, T.A., (1981). 'Downward comparison principles in social psychology', Psychological Bulletin 90(2): 245-271.

Zagefka, H. (2009) 'The concept of ethnicity in socio-psychological research: definitional issues', International Journal of Intercultural Relations 33: 228-241. 